\title{
Stability Indicating Method for the Determination of Related Substances in Felodipine Solid Dosage Form and in the Drug Substance by RP-HPLC
}

Manoj Kumar Vadlamudi ${ }^{1,2}$ and Sangeetha Dhanaraj ${ }^{*}$

${ }^{1}$ School of Advanced Sciences, VIT University, Vellore-632014, Tamil Nadu, India

${ }^{2}$ Analytical Research and Development, Ashland (India) Private Limited, Hyderabad-500078, Telangana, India

\begin{abstract}
Background: Methods were not available in the monographs like United States Pharmacopeia, British pharmacopeia and European pharmacopeia and also in the literature for the determination of three related impurities namely Impurity A, B and C in Felodipine solid dosage form with a shorter runtime using RP-HPLC.
\end{abstract}

Method: A simple RP- HPLC method was developed and validated for the quantification of Felodipine Impurity $A, B$ and $C$ in Felodipine solid dosage form and in drug substance. This method was developed on waters alliance using Phenomenex Gemini column $\mathrm{C}_{18} 5 \mu \mathrm{m}, 150 \times 2.0 \mathrm{~mm}$ i.d, using the isocratic program with the mobile phase ratio of $0.02 \mathrm{mM}$ ammonium acetate adjusted to $\mathrm{pH} 5$ and acetonitrile $(55: 45, \mathrm{v} / \mathrm{v})$ with a flow rate of $0.7 \mathrm{~mL} / \mathrm{min}$. The $\lambda_{\max }$ is at $240 \mathrm{~nm}$.

Results: Forced degradation was performed as per ICH guidelines and no interference of the impurities with the known peaks was found. Precision was found between 0.1 and $0.2 \%$. The Limit of detection and quantification for Felodipine and impurity $A$; Impurity $B$ and $C$ were 0.05 and $0.15 \mu \mathrm{g} / \mathrm{mL}$ respectively. The linearity correlation coefficient was found to be $>0.999$ for Impurity A and Felodipine; Impurity B and C of concentration range $0.2-30.0$ $\mu \mathrm{g} / \mathrm{mL}$ and $0.2-8.0 \mu \mathrm{g} / \mathrm{mL}$ respectively. The method accuracy was assessed for Felodipine and its impurities at four levels (LOQ, $50 \%, 100 \%$ and $150 \%$ ) and the recovery ranged from $95 \%$ to $106 \%$.

Conclusion: The method was found to be precise, reliable, accurate and robust.

Keywords: Felodipine; Impurity A; Impurity B; Impurity C; Forced degradation; Validation; RP-HPLC

\section{Introduction}

Hypertension is an important risk factor for atherosclerosis and the beneficial effects of lowering blood pressure on the vascular morbidity and mortality is well documented and demonstrated. Felodipine (FD) is chemically referred to as 3-ethyl 5-methyl 4-(2,3-dichlorophenyl) -2,6-dimethyl-1,4-dihydropyridine-3,5-dicarboxylic is an antihypertensive drug with molecular formula $\mathrm{C}_{18} \mathrm{H}_{19} \mathrm{Cl}_{2} \mathrm{NO}_{4}$ and molecular weight $384.254 \mathrm{~g} / \mathrm{mol}$ (Table 1) [1,2]. FD decreases arterial smooth muscle contractility and subsequent vasoconstriction by inhibiting the influx of calcium ions through voltage-gated L-type calcium channels. FD may be used to treat mild to moderate essential hypertension [3] FD, a new generation calcium channel antagonist, belonging to the class of dihydropyridines, is a practical advance in the treatment of hypertension $[4,5]$. FD is a highly vasodilative calcium antagonist that effectively reduces arterial blood pressure [6].

There were no methods listed in the USP, EP and BP monographs as well as in the literature for the determination of three impurities namely Impurity A (Imp A), Impurity B (Imp B) and Impurity C (Imp C) in FD solid dosage form with shorter runtime. USP and BP monographs lists the determination of Imp-A only and The EP monograph list the determination of three impurities (Imp A, B and C) but, only for bulk drug and not for the formulation and also the runtime was about 30 min.

The goal of the study was to provide a stability indicating method for the quantification of three related substances (Imp A, B and C) in drug substance and in solid dosage form with shorter runtime.

\section{Experimental}

\section{Chemicals and reagents}

Acetonitrile (HPLC grade), disodium hydrogen orthophosphate, acetic acid and ammonium acetate were obtained from Merck Chemicals. Standard FD, Imp A, B and C were obtained from Ashland India Private Limited, Hyderabad, Telangana, India. All the other chemicals were of analytical grade and Milli-Q water was used.

\section{Instrument}

HPLC alliance Waters e2695 with photodiode array detector.

\section{Chromatographic conditions}

The Chromatography was performed by using a mobile phase having a fixed combination of $0.02 \mathrm{mM}$ ammonium acetate (adjusted to $\mathrm{pH} 5$ with glacial acetic acid) and acetonitrile $(55: 45, \mathrm{v} / \mathrm{v})$ with a flow rate of $0.7 \mathrm{~mL} / \mathrm{min}$ was used and equipped with Phenomenex Gemini column C18 $5 \mu \mathrm{m}, 150 \times 2.0 \mathrm{~mm}$ i.d. The wavelength maximum was at $240 \mathrm{~nm}$ and the column temperature used was $25^{\circ} \mathrm{C}$ and the total run time was $15 \mathrm{~min}$.

\section{Sample preparation}

Twenty tablets were weighed and finely powdered, and amount of powder equivalent to $50 \mathrm{mg}$ FD was accurately weighed and transferred

*Corresponding author: Sangeetha Dhanaraj, School of Advanced Sciences VIT University, Vellore-632014, Tamil Nadu, India, Tel: 914162243091/93; E-mail: dsangeetha@vit.ac.in

Received March 29, 2016; Accepted May 01, 2016; Published May 08, 2016

Citation: Vadlamudi MK, Dhanaraj S (2016) Stability Indicating Method for the Determination of Related Substances in Felodipine Solid Dosage Form and in the Drug Substance by RP-HPLC. J Bioequiv Availab 8: 153-166. doi:10.4172/ jbb.1000287

Copyright: (C) 2016 Vadlamudi MK, et al. This is an open-access article distributed under the terms of the Creative Commons Attribution License, which permits unrestricted use, distribution, and reproduction in any medium, provided the original author and source are credited. 
Citation: Vadlamudi MK, Dhanaraj S (2016) Stability Indicating Method for the Determination of Related Substances in Felodipine Solid Dosage Form and in the Drug Substance by RP-HPLC. J Bioequiv Availab 8: 153-166. doi:10.4172/jbb.1000287

to a $50 \mathrm{~mL}$ volumetric flask and about $30 \mathrm{~mL}$ of acetonitrile was added and sonicated for 15 minutes, the solution was made up to the mark using acetonitrile. The solution was centrifuged at $4500 \mathrm{rpm}$ for 10 minutes and the clear supernatant was filtered through a $0.45 \mu \mathrm{m}$ membrane filter and injected onto the HPLC system.

\section{Method development and optimization of chromatographic conditions}

Concentration of $\mathrm{FD}, \operatorname{Imp} \mathrm{A}, \mathrm{B}$ and $\mathrm{C}$ used are as shown in the Table 2.

Trial-1: Since the pKa of FD is 5.4, hence $\mathrm{pH}$ of $0.02 \mathrm{mM}$ disodium hydrogen phosphate as mobile phase $\mathrm{A}$ was adjusted to $\mathrm{pH} 5$ using $10 \%$<smiles>CCOC(=O)C1=C(C)NC(C)=C(C(=O)OC)C1c1cccc(Cl)c1Cl</smiles>

FD: 3,5-Pyridinedicarboxylic acid 4-(2,3-dichlorophenyl)-1,4-dihydro-2,6dimethyl-, ethyl methyl ester, ( \pm )<smiles>CCOC(=O)c1c(C)nc(C)c(C(=O)OC)c1-c1cccc(Cl)c1Cl</smiles>

Imp A: (ethyl methyl 4-(2,3-dichlorophenyl)-2,6-dimethylpyridine-3,5dicarboxylate)<smiles>COC(=O)C1=C(C)NC(C)=C(C(=O)OC)C1c1cccc(Cl)c1Cl</smiles>

Imp B: 4-(2,3-Dichlorophenyl)-1,4-dihydro-2,6-dimethyl-3,5-pyridinedicarboxylic Acid 3,5-Dimethyl Ester;<smiles>CCOC(=O)C1=C(C)NC(C)=C(C(=O)OCC)C1c1cccc(Cl)c1Cl</smiles>

Imp C: 4-(2,3-Dichlorophenyl)-1,4-dihydro-2,6-dimethyl-3,5-pyridinedicarboxylic Acid 3,5-Diethyl Ester:

Table 1: Chemical names and structures of FD, Imp A, B and C.

\begin{tabular}{|c|c|c|}
\hline \multirow{2}{*}{ Compound } & \multicolumn{2}{|c|}{ Concentration } \\
\cline { 2 - 3 } & $\mathbf{m g} / \mathbf{m L}$ & $\boldsymbol{\mu g} / \mathbf{m L}$ \\
\hline FD & 1.0 & 1000 \\
\hline Imp A & 0.02 & 20 \\
\hline Imp B & 0.005 & 5 \\
\hline Imp C & 0.005 & 5 \\
\hline
\end{tabular}

Table 2: Concentration of FD and its impurities. $\mathrm{v} / \mathrm{v}$, orthophoporic acid) and acetonitrile as mobile phase B equipped with column X-Bridge $\mathrm{C} 18$ having dimensions $33 \mathrm{~mm} \times 3.5 \mathrm{~mm}$ i.d., $5 \mu \mathrm{m}$ particle size, flow rate of $1.0 \mathrm{~mL} / \mathrm{min}$. The wavelength maximum found at $240 \mathrm{~nm}$.

Trial-2: Continued to trial-1, here $\mathrm{X}$-Terra $\mathrm{C}_{18}$ column having dimensions $20 \mathrm{~mm} \times 3.5 \mathrm{~mm}$ i.d., $4.6 \mu \mathrm{m}$ particle size with the same mobile phase A and B as in trial-1 was used but, here the ratios were altered to get better resolution in a shorter run time.

Trial-3: From trial- 1 and 2 shows it was difficult to get the separation in a shorter runtime with good resolution. So phenomenex Gemini $\mathrm{C}_{18}$ column having dimensions $150 \mathrm{~mm} \times 2.0 \mathrm{~mm}$ i.d., $5 \mu \mathrm{m}$ particle size with $5.0 \mathrm{pH} 0.02 \mathrm{mM}$ ammonium acetate (adjusted $\mathrm{pH}$ with glacial acetic acid) as mobile phase $\mathrm{A}$ and acetonitrile as mobile phase $\mathrm{B}$ was used, different ratios were altered to reach the better separation in a shorter runtime.

Forced degradation study: In order to demonstrate the method is stability indicating, forced degradation study was performed in different conditions as per ICH guidelines, hydraulic (acid, base and neutral), oxidation, thermal, sunlight, humidity and photolytic conditions.

Hydraulic condition: It is a chemical process that includes decomposition of a chemical compound by reaction with acid, base and water. Stress study was performed by refluxing tablet powder equivalent to $1 \mathrm{mg} / \mathrm{mL}$ of $\mathrm{FD}$ with $2 \mathrm{~N}$ hydrochloric acid, $2 \mathrm{~N}$ sodium hydroxide and water at $60^{\circ} \mathrm{C}$ for $5 \mathrm{~h}[7,8]$.

Oxidative condition: Oxidative study was performed by refluxing equivalent tablet powder $1 \mathrm{mg} / \mathrm{mL}$ of $\mathrm{FD}$ in $3 \%$ of hydrogen peroxide at $60^{\circ} \mathrm{C}$ for $5 \mathrm{~h} \mathrm{[7].}$

Photolytic conditions: Photolytic testing of drug substances and products was essential to demonstrate that light exposure does not affect the same. These studies were evaluated with $1 \mathrm{mg} / \mathrm{mL}$ of FD tablet powder by exposure to fluorescent conditions about 1.2 million $\mathrm{lx} h$ and $200 \mathrm{~W} \mathrm{~h} / \mathrm{m}^{2}$ light [7].

Sunlight condition: The sunlight testing of drug substances and products was essential to demonstrate that sunlight exposure does not affect on the same. The study was evaluated with $1 \mathrm{mg} / \mathrm{mL}$ of FD equivalent tablet powder by exposure to direct sunlight for 1 week [7].

Thermal conditions: A Thermal degradation study was carried with $1 \mathrm{mg} / \mathrm{mL}$ of FD equivalent tablet powder in a dry heat at higher temperatures $\left(105^{\circ} \mathrm{C}\right)$ for a time period of $72 \mathrm{~h}$.

Analytical method validation: Analytical method validation procedure to demonstrate that it is appropriate for its intended purpose [8]

Parameters: Specificity

- Detection and Quantitation Limit

- Linearity

- Precision

- Repeatability

- Intermediate Precision

- Reproducibility

- Accuracy

- Range

- Robustness

- System suitability determination

- Solution stability studies 
Citation: Vadlamudi MK, Dhanaraj S (2016) Stability Indicating Method for the Determination of Related Substances in Felodipine Solid Dosage Form and in the Drug Substance by RP-HPLC. J Bioequiv Availab 8: 153-166. doi:10.4172/jbb.1000287

Specificity: Specificity is the ability to assess unequivocally the analyte in the presence of components which might include impurities, degradants and matrix [9].

Detection and quantification limit: The detection limit of an individual analytical procedure is the lowest amount of analyte in a sample which can be detected, but need not to be necessarily quantitative as an exact value. The quantitation limit of an individual analytical procedure is the lowest amount of analyte in a sample which can be quantitatively determined with suitable precision and accuracy [6].

Linearity: The Linearity of a method is its ability to obtain test results that are directly proportional to the sample concentration over a given range of concentration [9].

Precision: The precision is considered at three levels of repeatability, intermediate precision and reproducibility should be established using the homogeneous sample. The precision of an analytical procedure is expressed as the variance, standard deviation or coefficient of variation [9].

Accuracy: The accuracy of an analytical procedure is the closeness of the test results obtained by that procedure to the true value [9].

Range: The range of an analytical procedure is the interval between the upper and lower concentration (amounts) of analyte in the sample (including these concentrations) for which it has been demonstrated that the analytical procedure has a suitable level of precision, accuracy and linearity [6].

Robustness: The robustness is not a required validation element as per USP General Chapter $<1225>$ but is described in this chapter. This analysis is therefore an optional validation element. The robustness of an analytical procedure are a measure of its capacity to remain unaffected by small, but deliberate variations in method parameters and are an indication of its reliability during normal usage [8].

System suitability determination: System suitability tests were performed to ensure that the HPLC system and analytical procedure are capable of providing deliberate and consistent results.

Solution stability: The each impurity at specified concentrations with respect to the sample concentration were analyzed at different intervals of 1,2 and 3 days at room temperature $\left(25^{\circ} \mathrm{C}\right)$ and in refrigerator $\left(5^{\circ} \mathrm{C}\right)$ conditions in order to know the stability of the sample solution as well as mobile phase stability at room temperature.

\section{Results and Discussion}

\section{Development and optimization of chromatographic condi- tions}

Method development and optimized from trial 1 to 3.

Trial-1: Here, for case 1, 2 and 3 unknown and Imp B peaks were found to be merging. In case 4 the peaks were well separated but the run time was about $60 \mathrm{~min}$ to elute all the impurities and also broadened peaks were observed. Details of the resolution are in Table 3 and respective chromatograms are shown in Figures 1-4.

Trial-2: Here, the peaks were merging in both the case 1 and 2 . An unknown peak eluted at retention time of $2.399 \mathrm{~min}$ in case 2 was merged with Imp B. Details of the resolution are in Table 4 and respective chromatograms are shown in Figures 5 and 6.

Trial-3: Here, better separation was obtained in case 3 and 5, but in case 5 shorter run time as well as good resolution and theoretical plates were obtained. Details of the resolution are in Tables 5 and 6 and respective chromatograms are shown in Figures 7-11.

The developed method was found to be more economical using the set parameters.

\section{Forced degradation study}

FD was observed degradable in thermal condition only. The purity angle was less than the threshold and also no purity flag was observed in all the conditions. The mass balance is more than $99.5 \%$, hence the method was found to be stability indicating to get rid of all the degradants from the known and unknown impurities. The results are tabulated in Table 7 and respective chromatograms are shown in Figures 12-19.

\begin{tabular}{|c|c|c|c|c|c|c|}
\hline Case\# & $\% A$ & $\%$ B & $\begin{array}{l}\text { Flow rate } \\
\mathrm{mg} / \mathrm{mL}\end{array}$ & $\begin{array}{c}\text { Resolution between Imp B } \\
\text { and Imp A }\end{array}$ & $\begin{array}{l}\text { Resolution between FD and } \\
\operatorname{Imp} A\end{array}$ & $\begin{array}{c}\text { Resolution between FD } \\
\text { and Imp C }\end{array}$ \\
\hline Case 1 & 50 & 50 & 1.0 & 1.2 & 3.4 & 3.7 \\
\hline Case 2 & 55 & 45 & 1.0 & 3.0 & 1.9 & 4.1 \\
\hline Case 3 & 60 & 40 & 1.0 & 3.3 & 2.4 & 5.2 \\
\hline Case 4 & 65 & 35 & 1.0 & 2.7 & 2.7 & 5.0 \\
\hline
\end{tabular}

Table 3: Detailed conditions for trial-1.

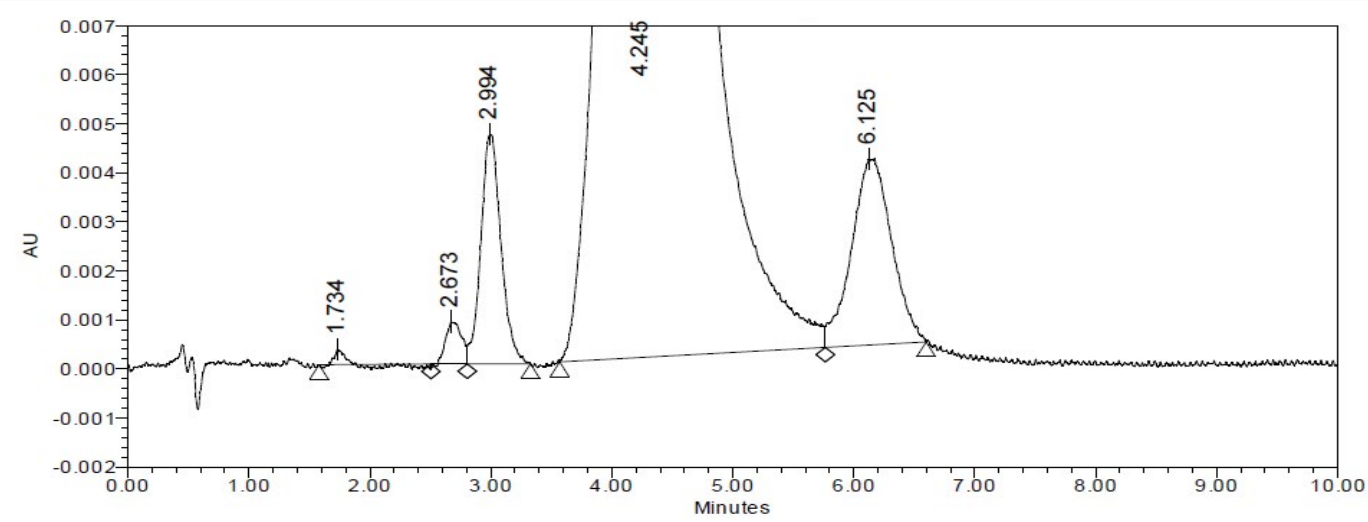

Figure 1: Chromatogram represents case 1 from trial 1 
Citation: Vadlamudi MK, Dhanaraj S (2016) Stability Indicating Method for the Determination of Related Substances in Felodipine Solid Dosage Form and in the Drug Substance by RP-HPLC. J Bioequiv Availab 8: 153-166. doi:10.4172/jbb.1000287

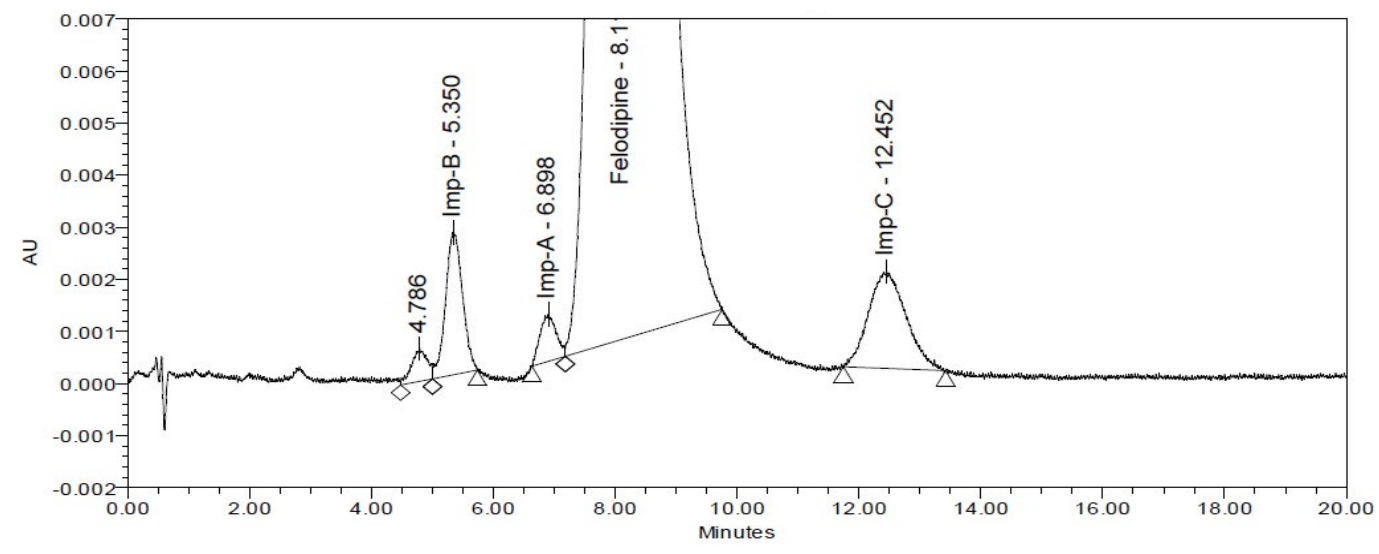

Figure 2: Chromatogram represents case 2 from trial 1.

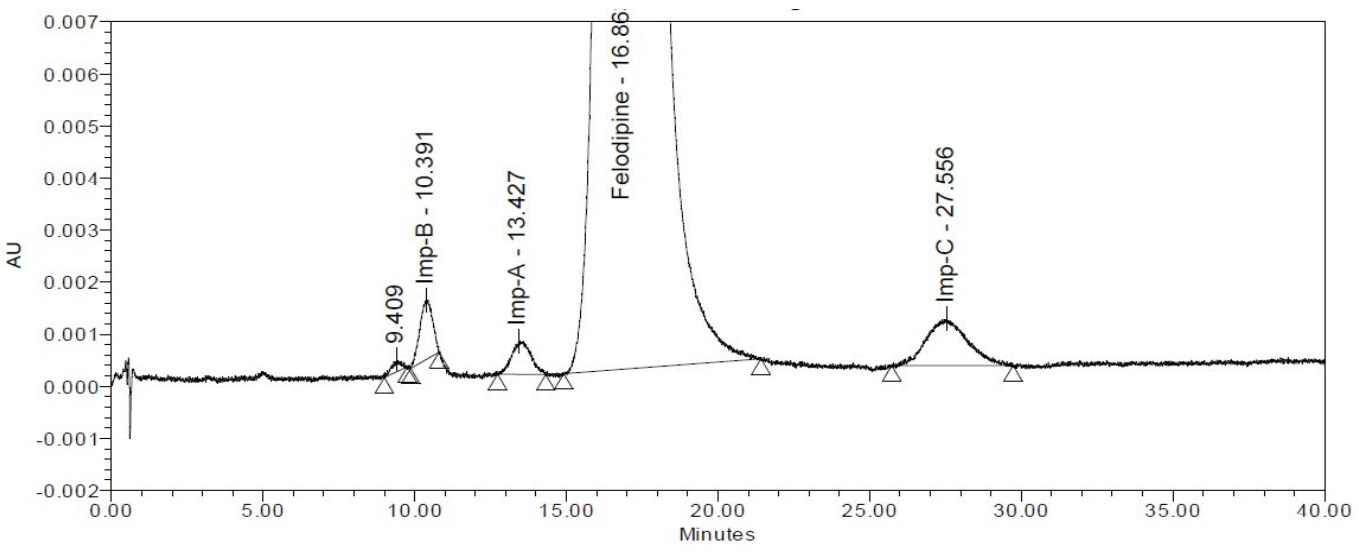

Figure 3: Chromatogram represents case 3 from trial 1.

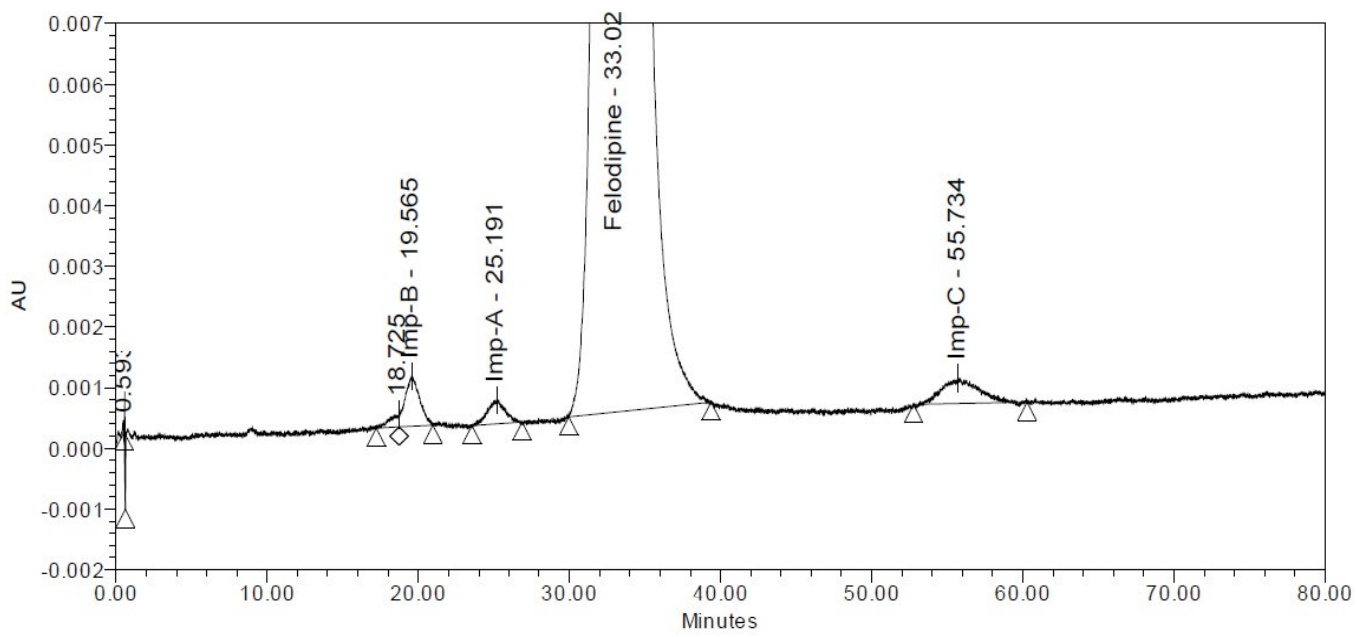

Figure 4: Chromatogram represents case 4 from trial 1.

\begin{tabular}{|c|c|c|c|c|c|c|}
\hline Case\# & $\%$ A & \%B & $\begin{array}{c}\text { Flow rate } \\
\mathbf{m g} / \mathbf{m L}\end{array}$ & $\begin{array}{c}\text { Resolution between Imp B } \\
\text { and Imp A }\end{array}$ & $\begin{array}{c}\text { Resolution between FD and } \\
\text { Imp A }\end{array}$ & $\begin{array}{c}\text { Resolution between FD and } \\
\text { Imp C }\end{array}$ \\
\hline Case 1 & 60 & 40 & 1 & 1.1 & 3.7 & 3.8 \\
\hline Case 2 & 65 & 35 & 1 & 1.2 & 4.4 & 4.5 \\
\hline
\end{tabular}

Table 4: Detailed conditions for trial-2. 


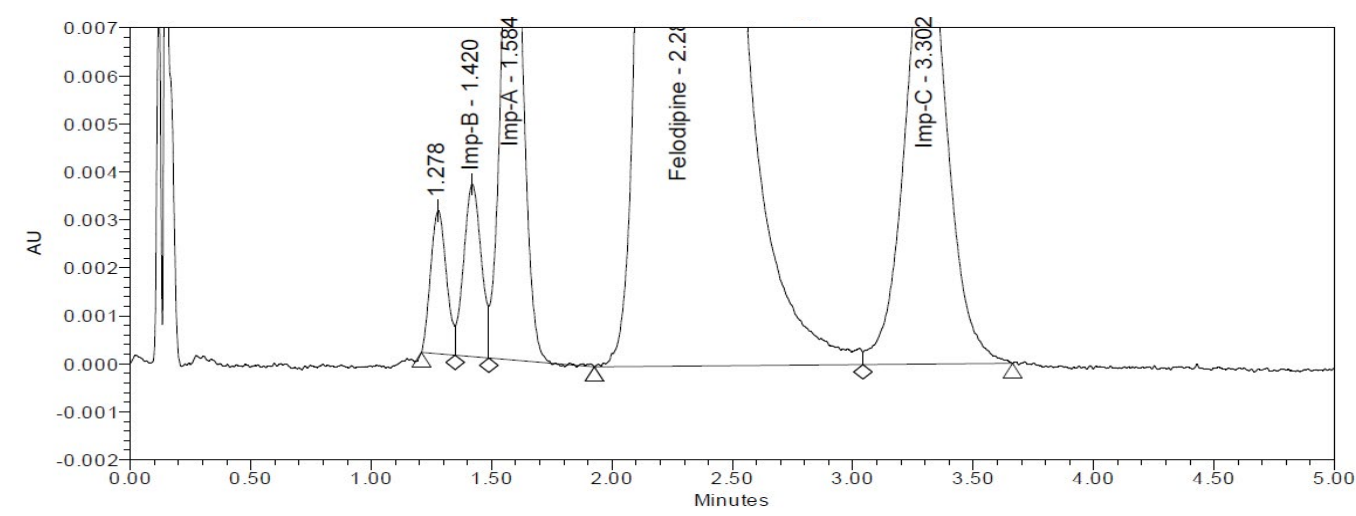

Figure 5: Chromatogram represents case 1 from trial 2.

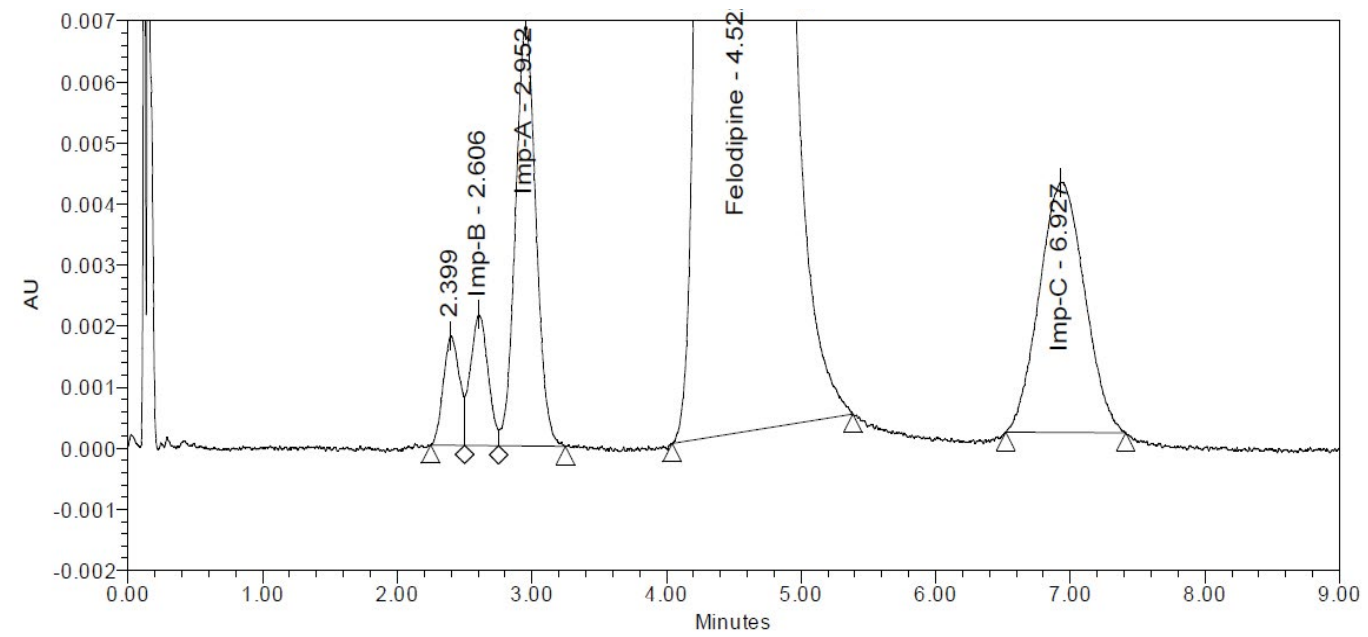

Figure 6: Chromatogram represents case 2 from trial 2.

\begin{tabular}{|c|c|c|c|c|c|c|}
\hline Case\# & \%A & \%B & $\begin{array}{c}\text { Flow rate } \\
\mathbf{m g} / \mathbf{m L}\end{array}$ & $\begin{array}{c}\text { Resolution between Imp B } \\
\text { and Imp A }\end{array}$ & $\begin{array}{c}\text { Resolution between FD and } \\
\text { Imp A }\end{array}$ & $\begin{array}{c}\text { Resolution between FD } \\
\text { and Imp C }\end{array}$ \\
\hline Case 1 & 50 & 50 & 0.5 & 3.5 & 2.1 & 6.0 \\
\hline Case 2 & 55 & 45 & 0.5 & 3.9 & 2.9 & 7.2 \\
\hline Case 3 & 60 & 40 & 0.5 & 4.6 & 4.1 & 8.7 \\
\hline Case 4 & 53 & 47 & 0.5 & 3.6 & 2.5 & 6.5 \\
\hline Case 5 & 55 & 45 & 0.7 & 3.5 & 2.6 & 6.5 \\
\hline
\end{tabular}

Table 5: Detailed conditions for trial-3.

\begin{tabular}{|c|c|c|c|c|c|c|c|}
\hline Case\# & \%A & \%B & $\begin{array}{c}\text { Flow rate } \\
\mathbf{m g} / \mathbf{m L}\end{array}$ & \multicolumn{3}{|c|}{ Theoretical plates } \\
\hline & & & & FD & Imp A & Imp B & Imp C \\
\hline Case 1 & 50 & 50 & 0.5 & 4651 & 5176 & 4664 & 5743 \\
\hline Case 2 & 55 & 45 & 0.5 & 5347 & 6261 & 5318 & 6489 \\
\hline Case 3 & 60 & 40 & 0.5 & 5776 & 7563 & 5802 & 6796 \\
\hline Case 4 & 53 & 47 & 0.5 & 4863 & 5533 & 4775 & 5736 \\
\hline Case 5 & 55 & 45 & 0.7 & 4606 & 5319 & 4478 & 5181 \\
\hline
\end{tabular}

Table 6: Detailed conditions for trial-3.

\section{Analytical method validation}

System suitability solution: The system suitability solution was prepared by taking $1.0 \mathrm{mg} / \mathrm{mL}$ of FD standard, $0.02 \mathrm{mg} / \mathrm{mL}$ of Imp A and $0.005 \mathrm{mg} / \mathrm{mL}$ of Imp C in acetonitrile. System suitability parameters are mentioned in Table 8 and respective chromatogram as shown Figure 20.

Relative response factor determination: The relative response factors (RRF) were determined for the concentrations ranging from 


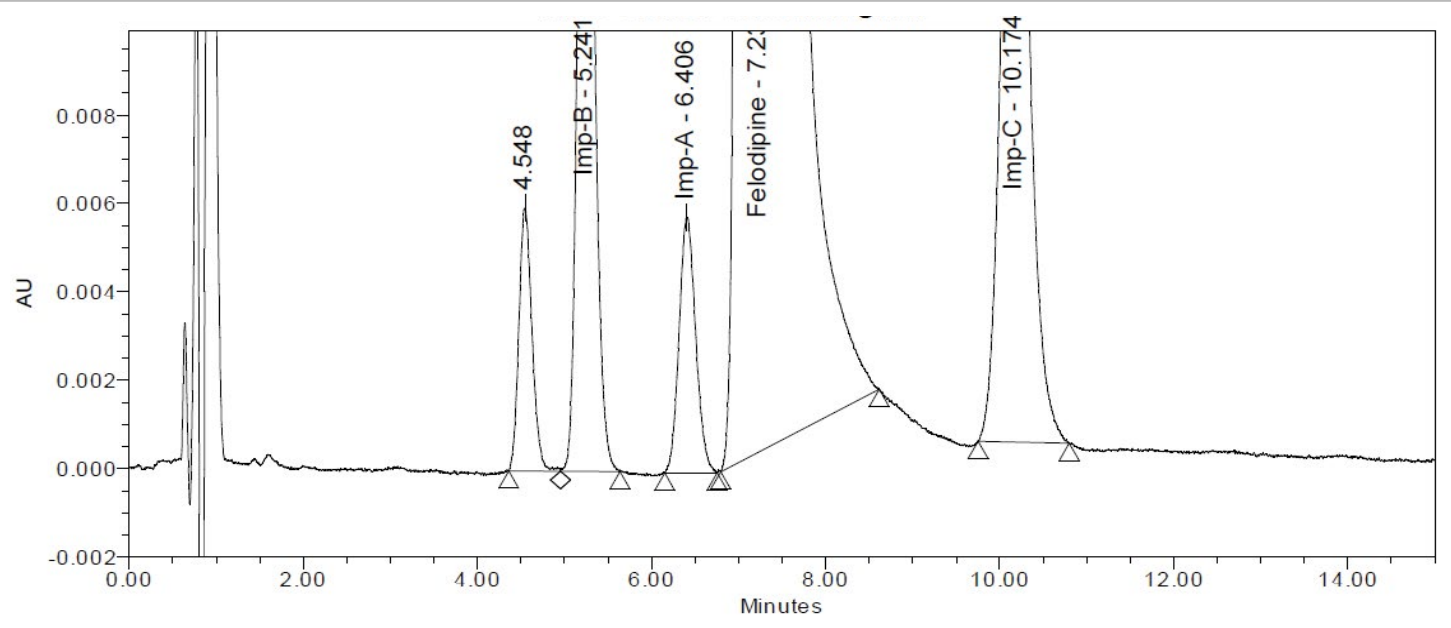

Figure 7: Chromatogram represents case 1 from trial 3.

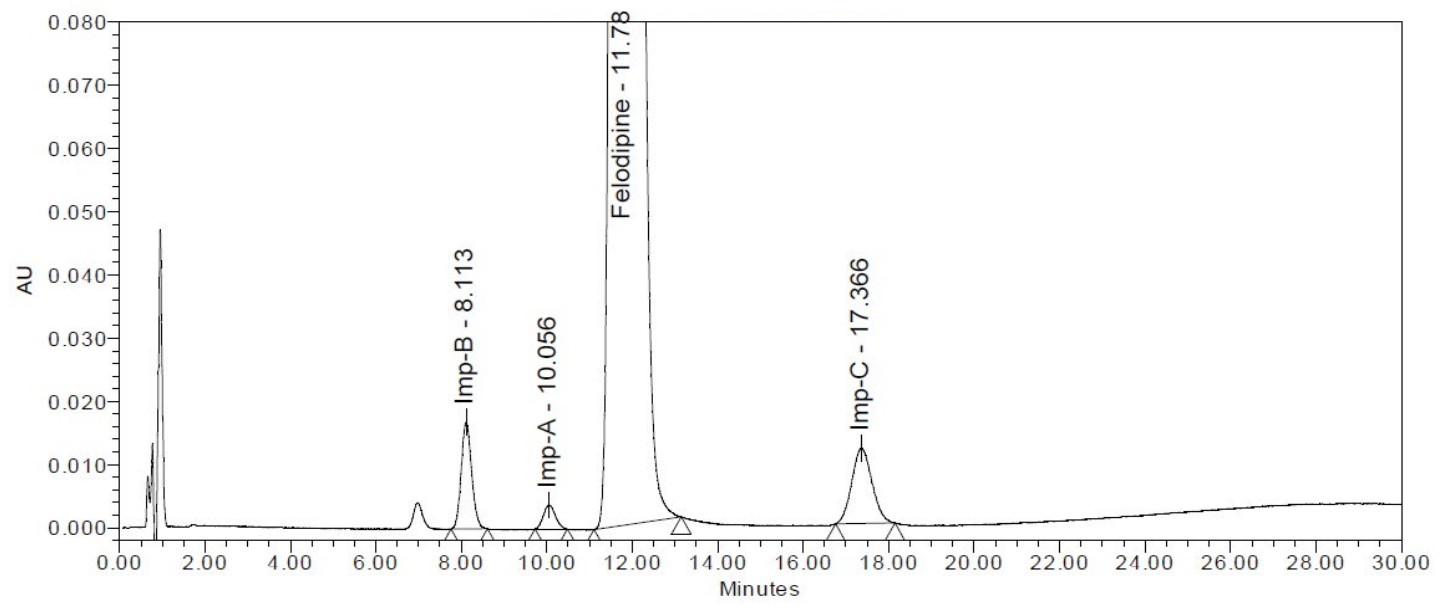

Figure 8: Chromatogram represents case 2 from trial 3.

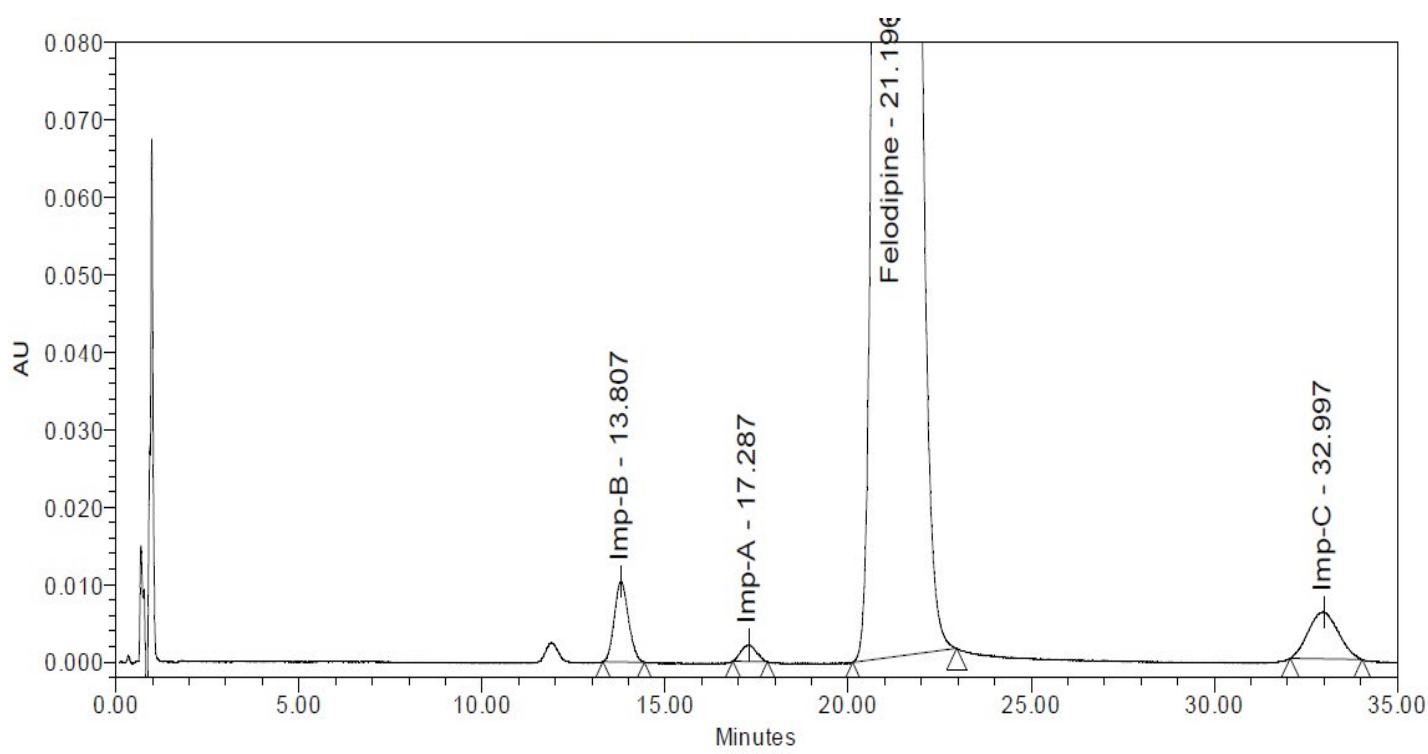

Figure 9: Chromatogram represents case 3 from trial 3. 


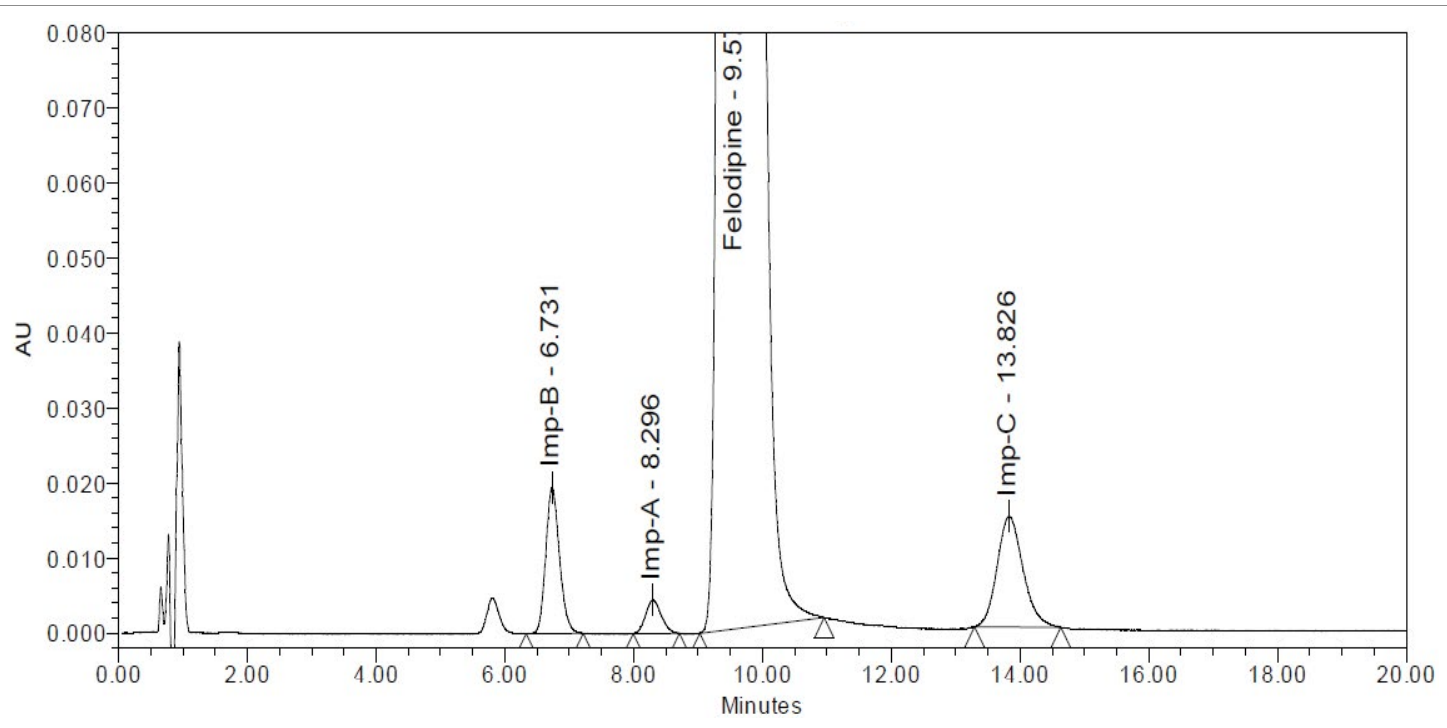

Figure 10: Chromatogram represents case 4 from trial 3.

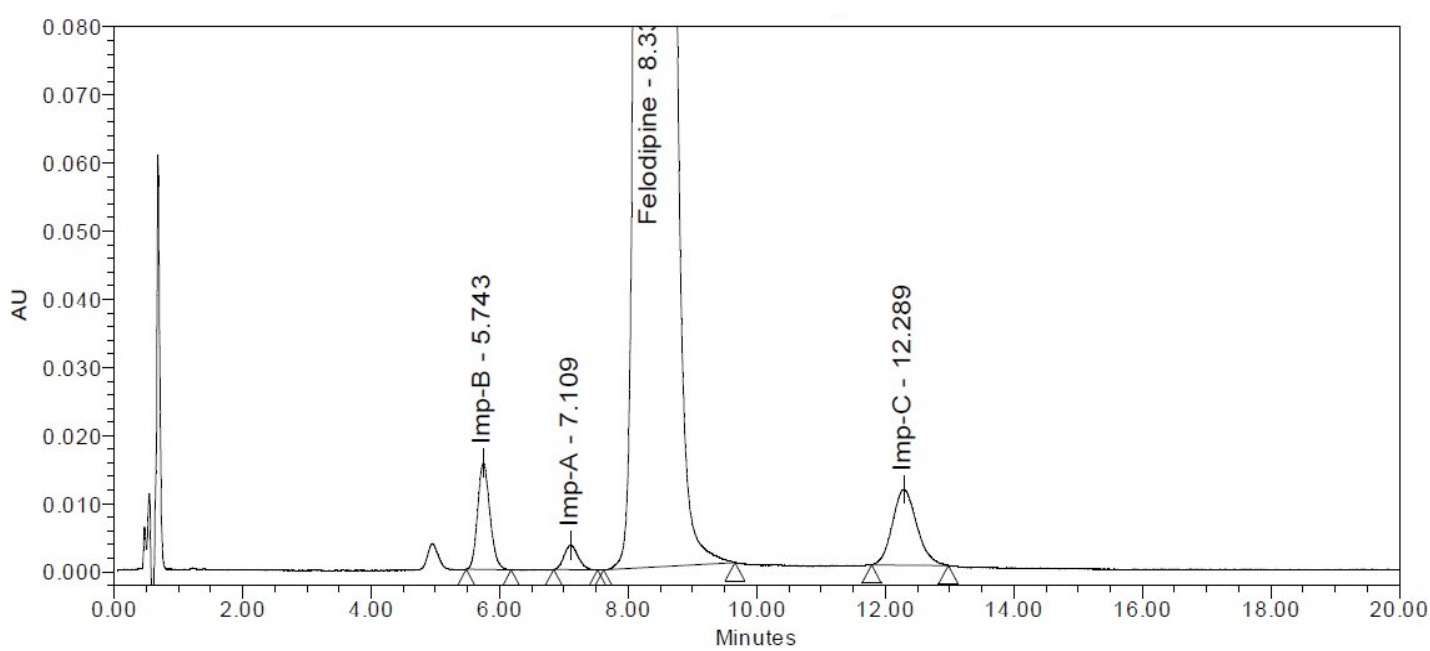

Figure 11: Chromatogram represents case 5 from trial 3.

\begin{tabular}{|c|c|c|c|}
\hline Condition & \% Net Degradation & Purity Angle & Purity Threshold \\
\hline Unstressed & 0.39 & 0.214 & 4.512 \\
\hline Acid stressed & 1.25 & 0.247 & 3.621 \\
\hline Water & 1.07 & 0.247 & 3.621 \\
\hline Base stressed & 0.58 & 0.403 & 4.690 \\
\hline Peroxide stressed & 0.5 & 0.083 & No \\
\hline Photolytic stressed & 0.44 & 0.334 & No \\
\hline Sunlight stressed & 0.42 & 0.300 & 4.907 \\
\hline Thermal stressed & 5.21 & 0.275 & 4.845 \\
\hline Humidity & 0.39 & 0.289 & No \\
\hline
\end{tabular}

Table 7: Results of degradation studies.

10 to $150 \%$ of specification level of each impurity with respect to the sample concentration and also FD sample as unknown. The RRF of each impurity was determined by dividing the slope of each impurity by the slope of the sample from linearity curve and the results obtained is as shown in Table 9.
Specificity: The specificity was performed for forced degradation study and no interference peaks were found in any of the conditions.

Detection and quantification limit: The Limit of detection (LOD) and Limit of quantification (LOQ) were calculated using the following equation as per ICH guidelines from the prediction linearity graph. 


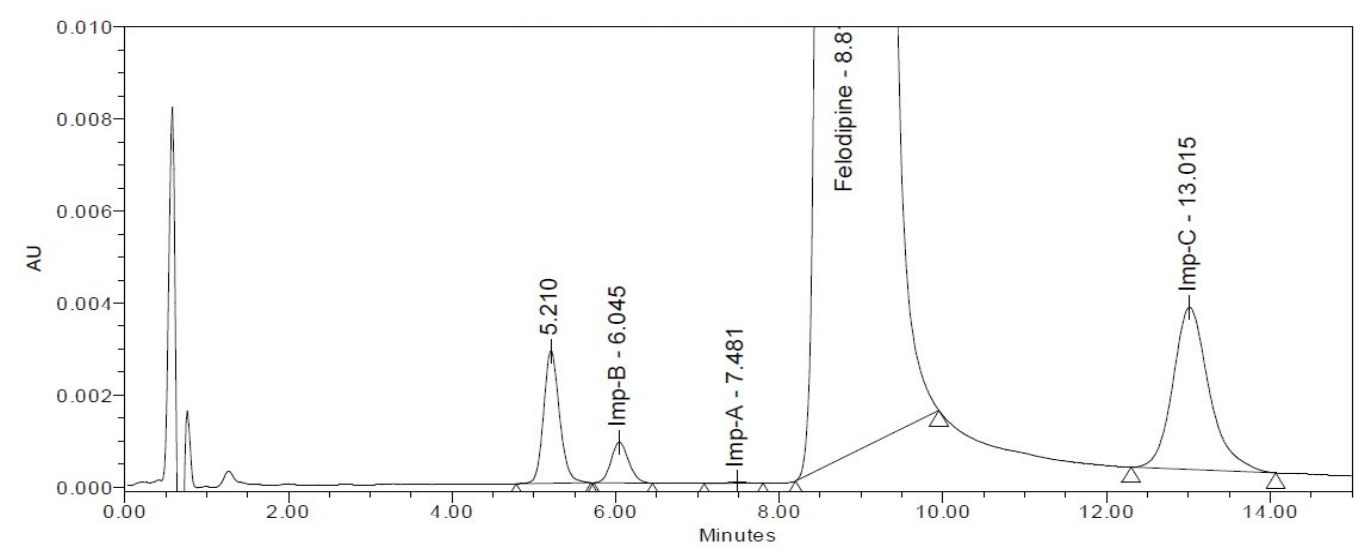

Figure 12: Chromatogram represents unstressed sample.

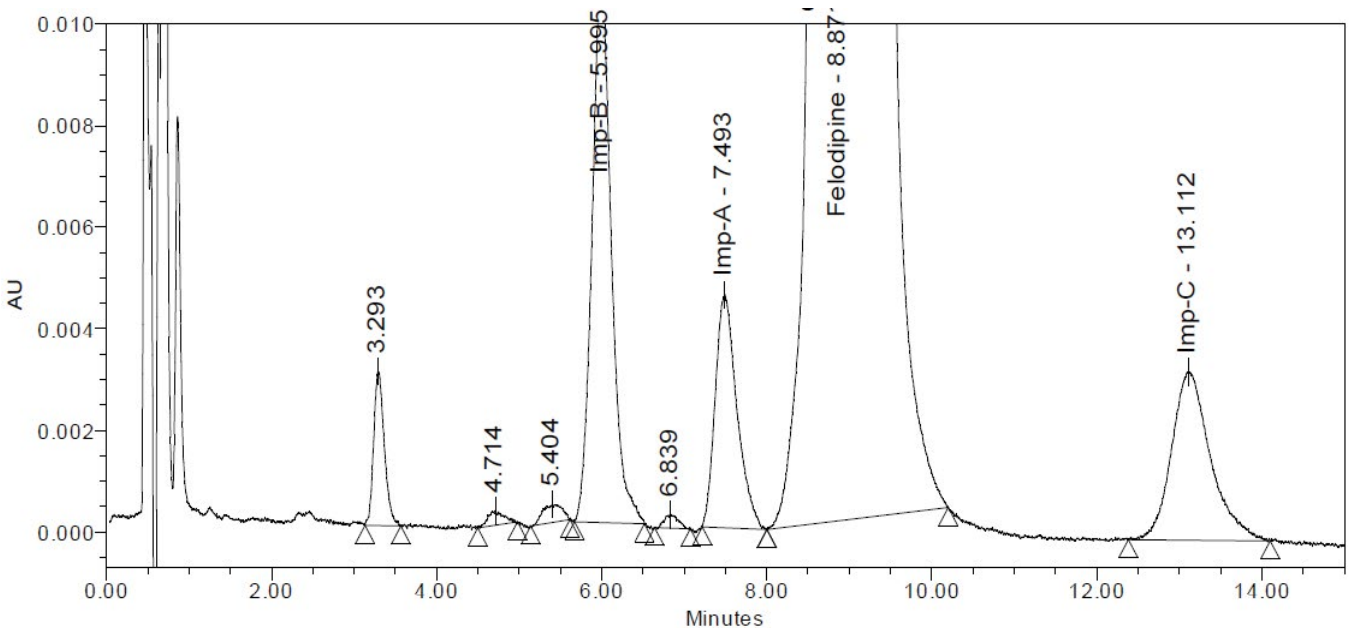

Figure 13: Chromatogram represents an acid stressed sample.

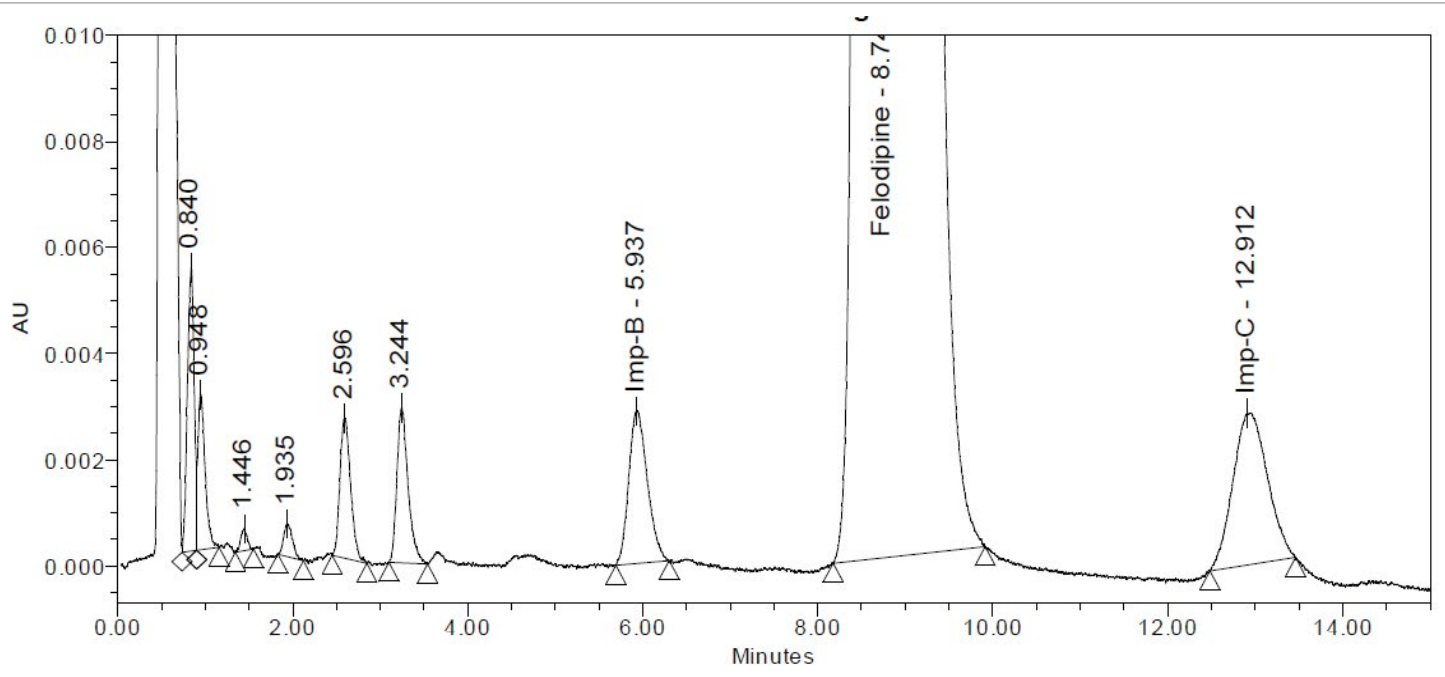

Figure 14: Chromatogram represents the base stressed sample.

$\mathrm{LOD}=3.3 \times \sigma / \mathrm{S}$

and $\mathrm{LOQ}=10 \times \sigma / \mathrm{S}$,
Where $\sigma$ is the standard deviation of y-intercept of the regression line and $\mathrm{S}$ is the slope of the calibration curve. Results are tabulated in Table 10 and respected chromatogram refers in Figure 21. 


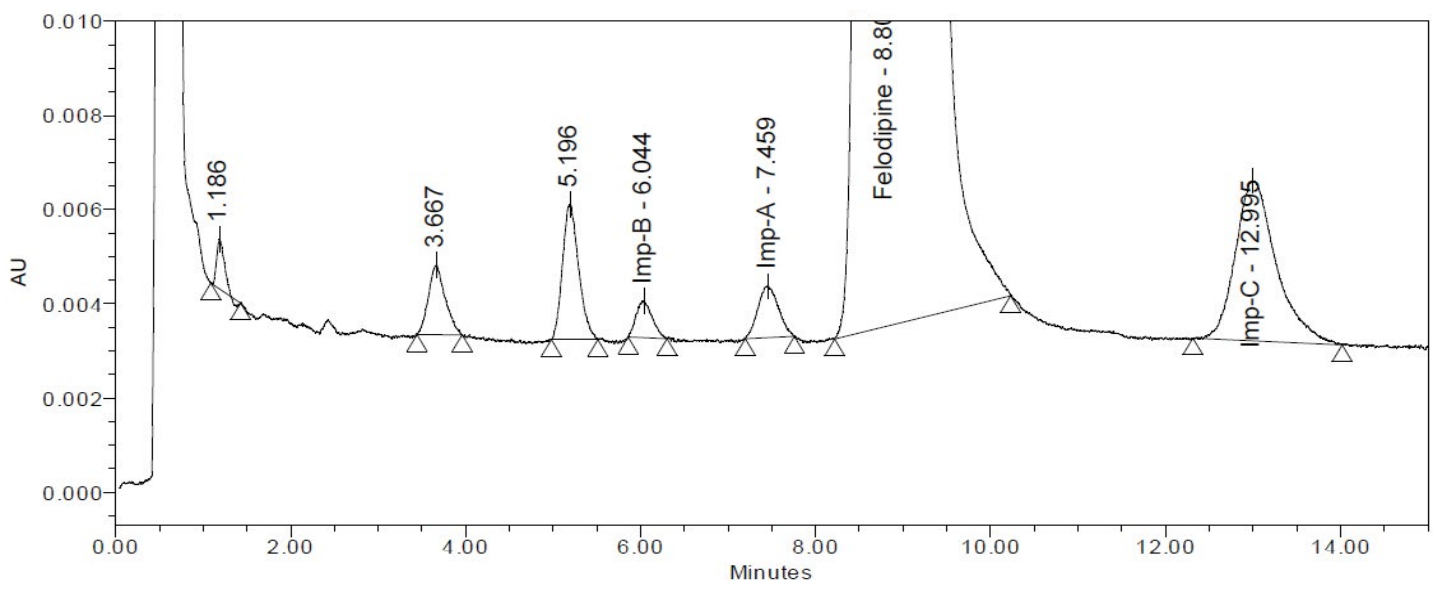

Figure 15: Chromatogram represents peroxide stressed sample.

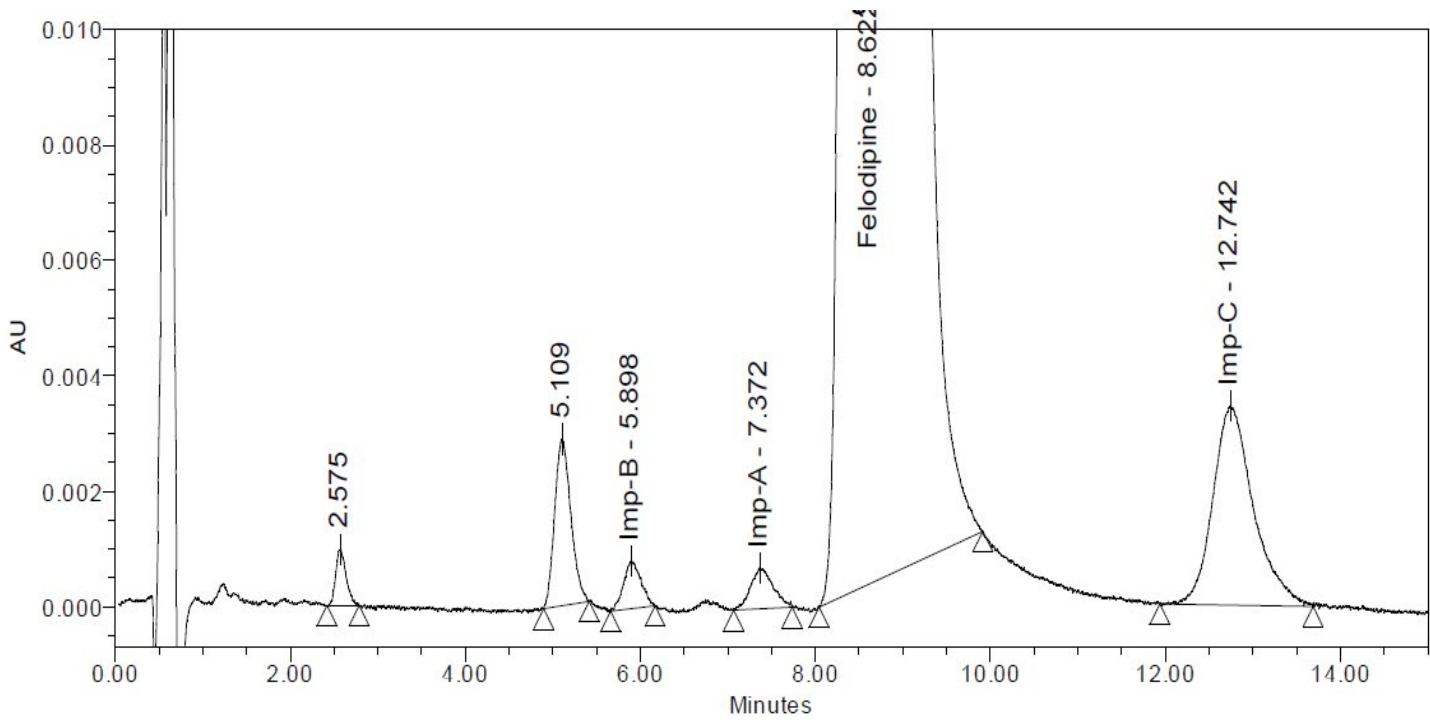

Figure 16: Chromatogram represents photolytic stressed sample.

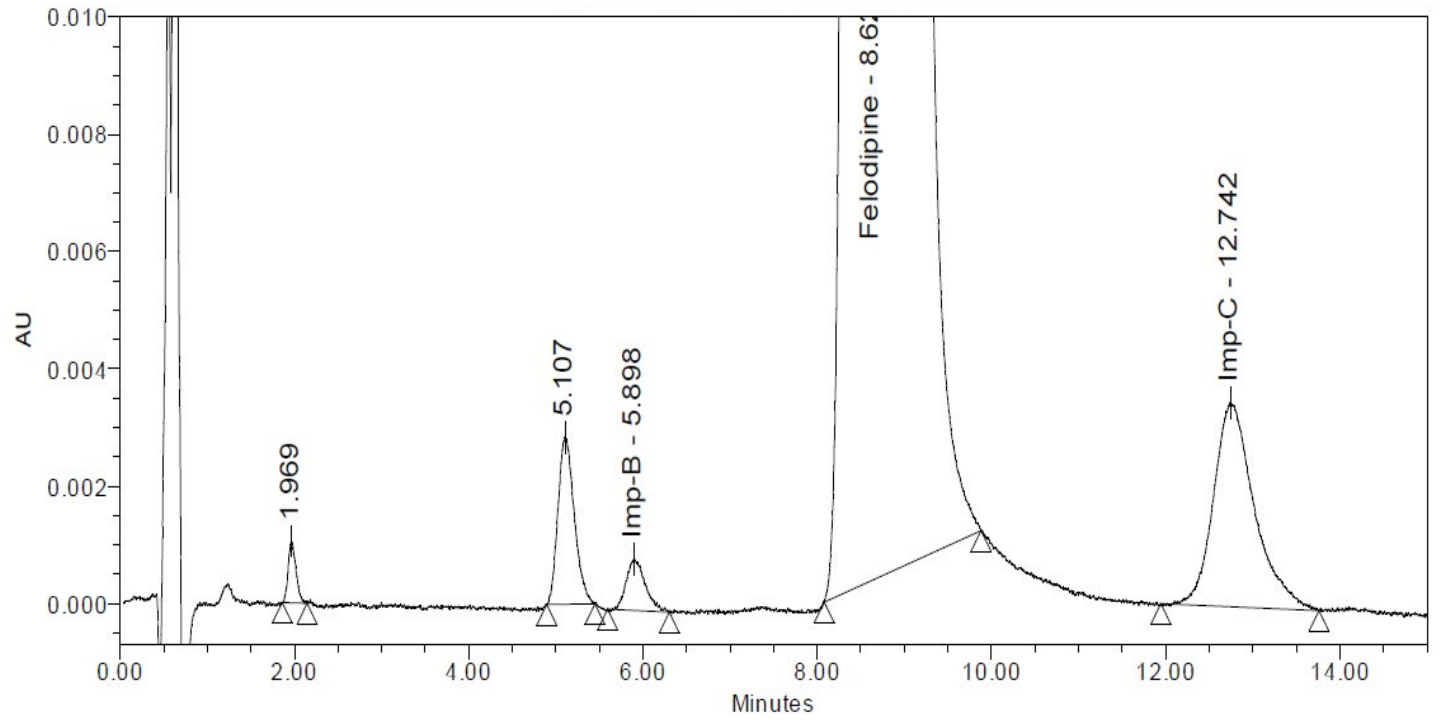

Figure 17: Chromatogram represents sunlight stressed sample. 


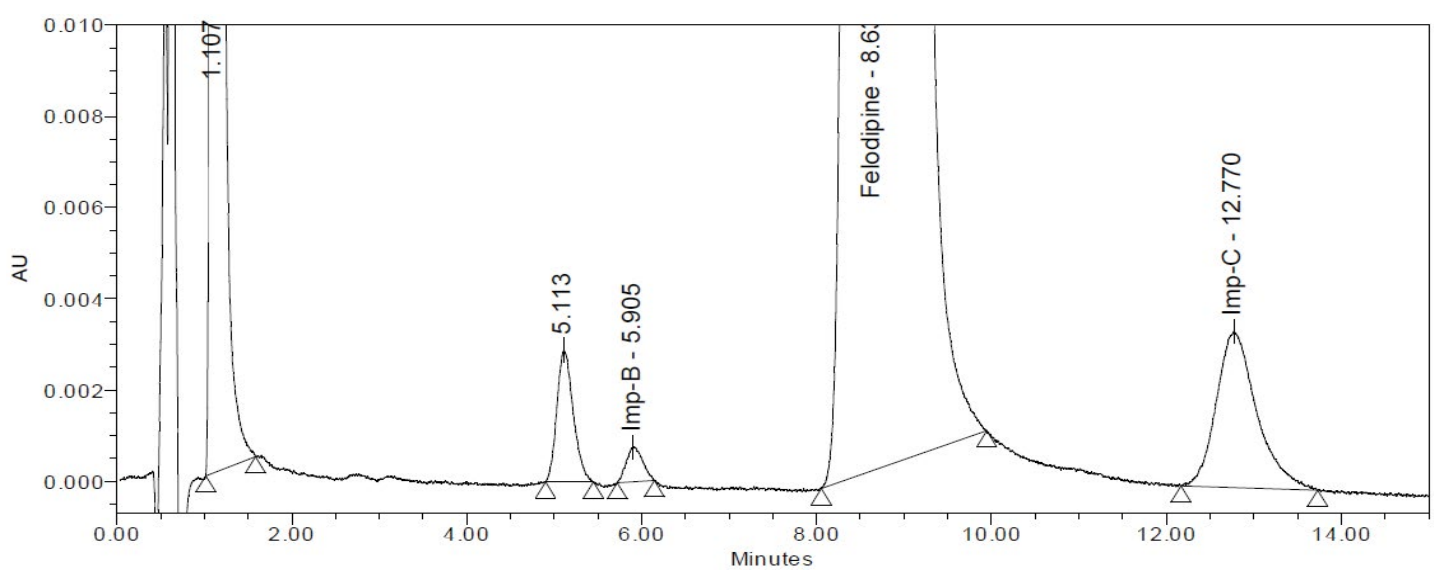

Figure 18: Chromatogram represents thermal stressed sample.

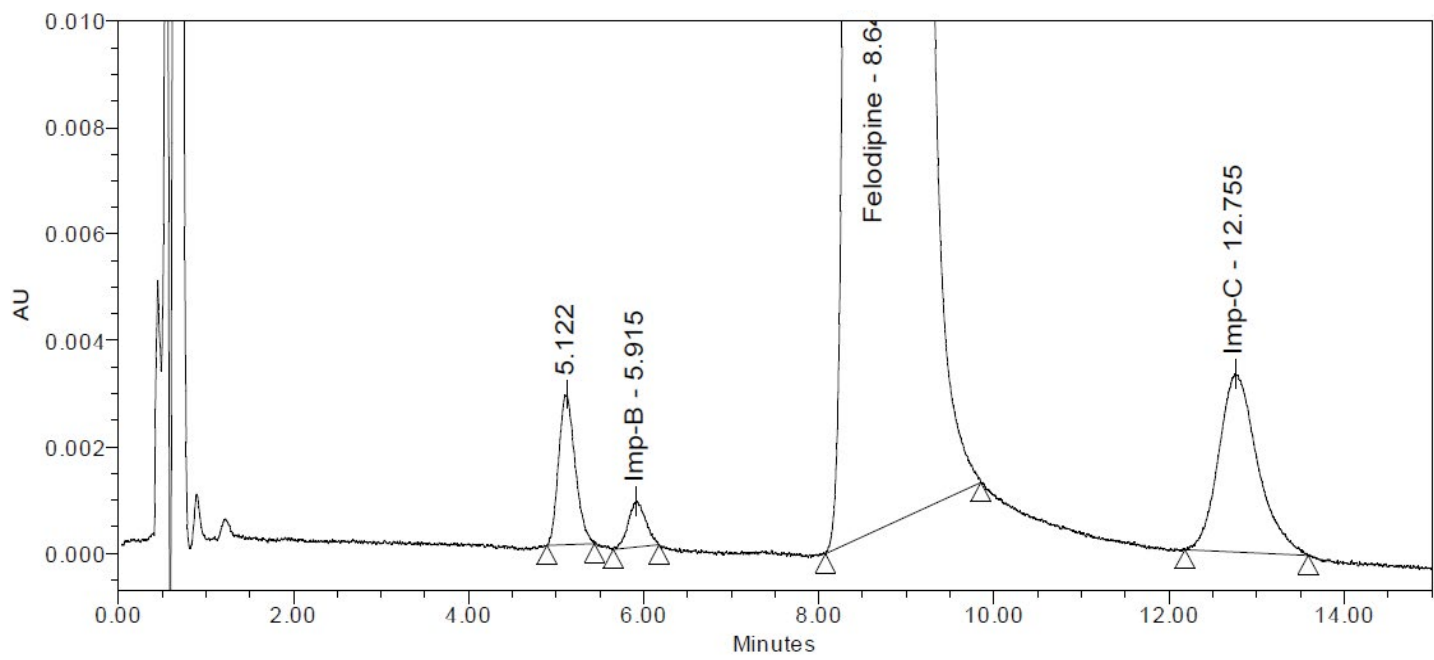

Figure 19: Chromatogram represents humidity stressed sample.

\begin{tabular}{|c|c|c|}
\hline Parameter & Specification & Results \\
\hline \multirow{3}{*}{ Theoretical plates $(\mathrm{N})$} & \multirow{3}{*}{$\geq 2000$} & FD: 4092 \\
\hline & & Imp A: 4140 \\
\hline & & Imp B: 4673 \\
\hline \multirow{3}{*}{ Tailing factor $(\mathrm{T})$} & \multirow{3}{*}{$<=1.5$} & FD: 1.25 \\
\hline & & $\operatorname{Imp} A: 1.16$ \\
\hline & & Imp B: 1.17 \\
\hline Resolution between Imp A and FD (R) & $\geq 1.5$ & 2.6 \\
\hline Resolution between FD and Imp C (R) & $\geq 1.5$ & 6.2 \\
\hline
\end{tabular}

Table 8: System suitability parameters.

Linearity: The linearity was performed from a range of LOQ concentration to $150 \%$ of each related substance specification with respect to the sample concentration spiked into the sample containing 1 $\mathrm{mg} / \mathrm{mL}$ and the correlation coefficient was found to be more than 0.999 . Results are presented in Table 11 and the graph is shown in Figure 22.

Repeatability: The repeatability was performed by taking 6 determinations along with sample and $100 \%$ specified concentration of each impurity with respect to the sample concentration. Results are shown in Table 12.

Intermediate precision: The intermediate precision was performed using different analyst on different days and using different instruments. Results are shown in Table 13.

Reproducibility: Reproducibility is performed as part of the test method transfer and will not be covered in this paper.

Accuracy: The accuracy was performed at LOQ, 50\%, 100\% and $150 \%$ of the specification of each impurity with respect to the sample concentration containing of $1 \mathrm{mg} / \mathrm{mL}$ of FD in three replicates. The results are shown in Table 14.

Robustness: Robustness was performed by varying the $\mathrm{pH}( \pm 0.1)$, 


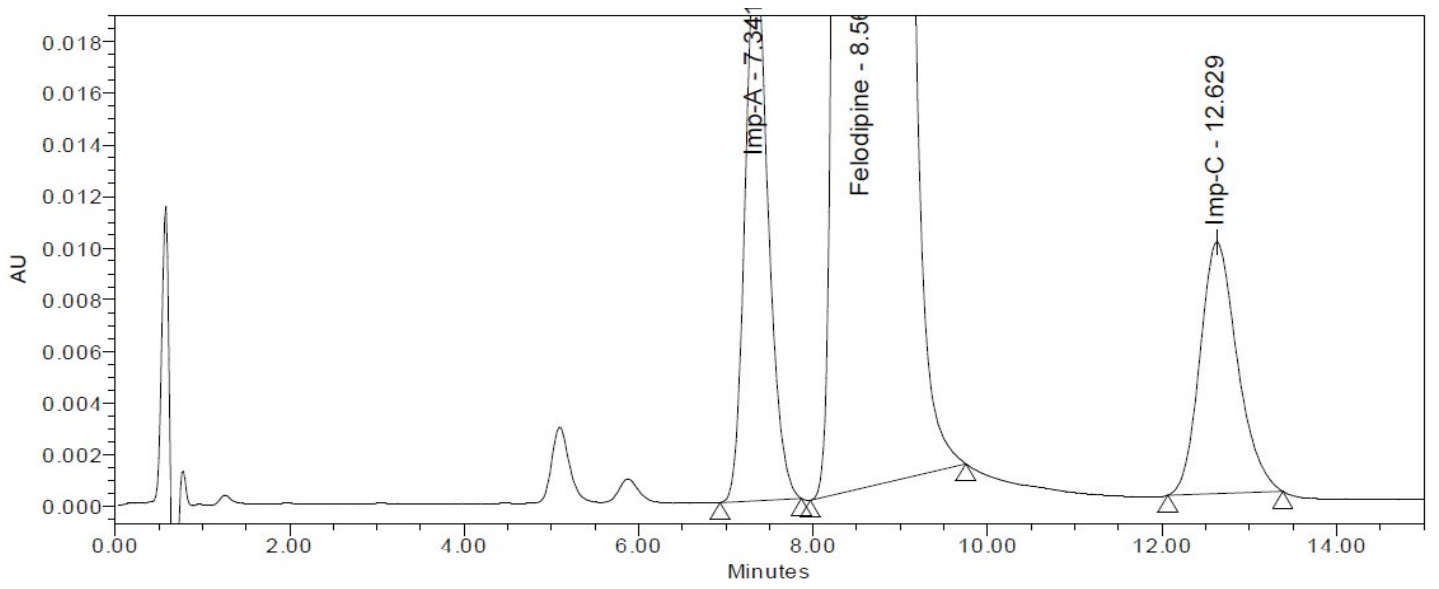

Figure 20: Chromatogram of system suitability solution.

\begin{tabular}{|c|c|c|}
\hline $\begin{array}{c}\text { Name of the } \\
\text { component }\end{array}$ & Relative retention time & Relative response factor \\
\hline FD & 1.00 & 1.00 \\
\hline Imp A & 0.85 & 0.42 \\
\hline Imp B & 0.69 & 0.92 \\
\hline Imp C & 1.48 & 0.86 \\
\hline
\end{tabular}

\begin{tabular}{|c|c|c|}
\hline Name of the component & \% LOD & \% LOQ \\
\hline FD as unknown & 0.005 & 0.015 \\
\hline Imp A & 0.005 & 0.015 \\
\hline Imp B & 0.005 & 0.015 \\
\hline Imp C & 0.005 & 0.015 \\
\hline
\end{tabular}

Table 9: Relative response factor determination.

Table 10: \% LOD and \% LOQ.

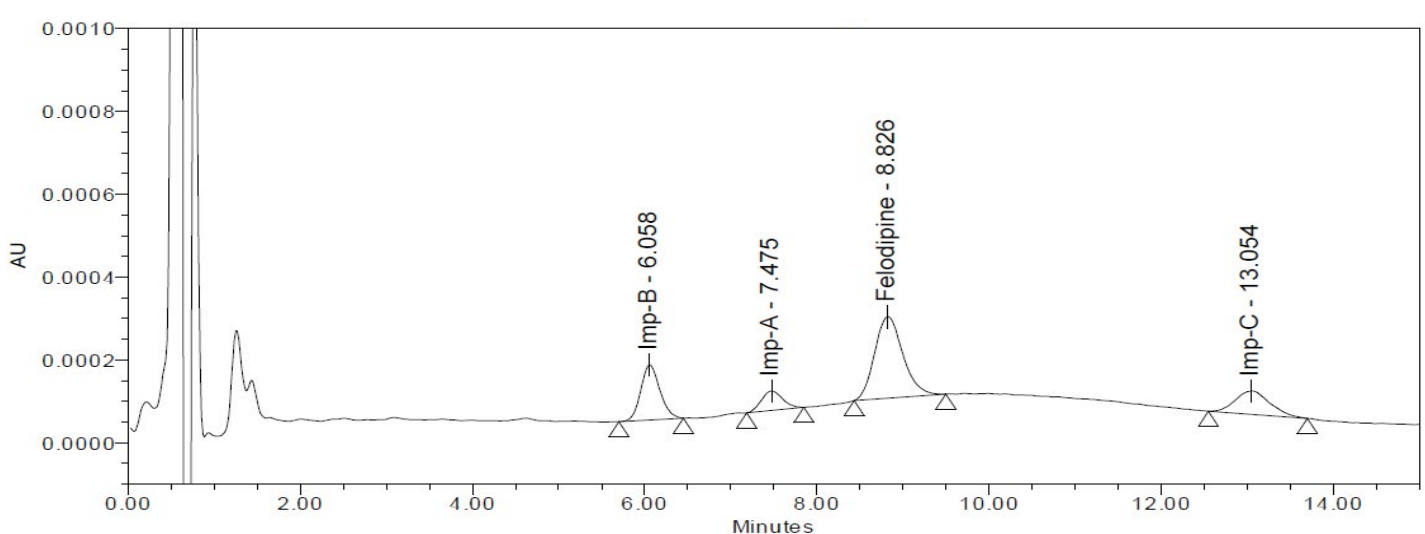

Figure 21: Chromatogram represents at LOD concentration peaks of FD and its impurities.

\begin{tabular}{|c|c|c|c|c|}
\hline Name of the component & Correlation coefficient & Slope & Intercept & Bias at 100\% \\
\hline FD as unknown & 0.999 & 41982 & 169 & 0.01 \\
\hline Imp A & 0.999 & 17875 & -1620 & 0.8 \\
\hline Imp B & 0.999 & 38648 & 1636 & 0.5 \\
\hline Imp C & 0.999 & 35077 & 9065 & 3.1 \\
\hline
\end{tabular}

Table 11: Linearity.

same column having different lot number, column temperature $( \pm$ $\left.5^{\circ} \mathrm{C}\right)$, wavelength $( \pm 2 \mathrm{~nm})$ and flow rate $( \pm 0.1 \mathrm{~mL} / \mathrm{min})$. The results are shown in Table 15.

Solution stability: The impurities were stable up to 3 days in refrigerator $\left(5^{\circ} \mathrm{C}\right)$ condition and up to 2 days at room temperature having the variations of not more than $10 \%$ of the initial value. The results are shown in Tables 16 and 17.

Sample analysis: Two different manufacturing drug substances and formulations were analyzed using this method to prove that the method is suitable for the regular analysis. The peaks are well separated and no interference was observed, since the results were found to be within the specification; hence the method is suitable for routine analysis. The results are tabulated in Table 18 .

\section{Conclusion}

A Stability indicating method was developed and validated for the determination of FD impurities namely Imp A, B and C in solid dosage form and also in drug substance. The developed method was very robust, accurate, precise and linear across the concentration range; 
Citation: Vadlamudi MK, Dhanaraj S (2016) Stability Indicating Method for the Determination of Related Substances in Felodipine Solid Dosage Form and in the Drug Substance by RP-HPLC. J Bioequiv Availab 8: 153-166. doi:10.4172/jbb.1000287
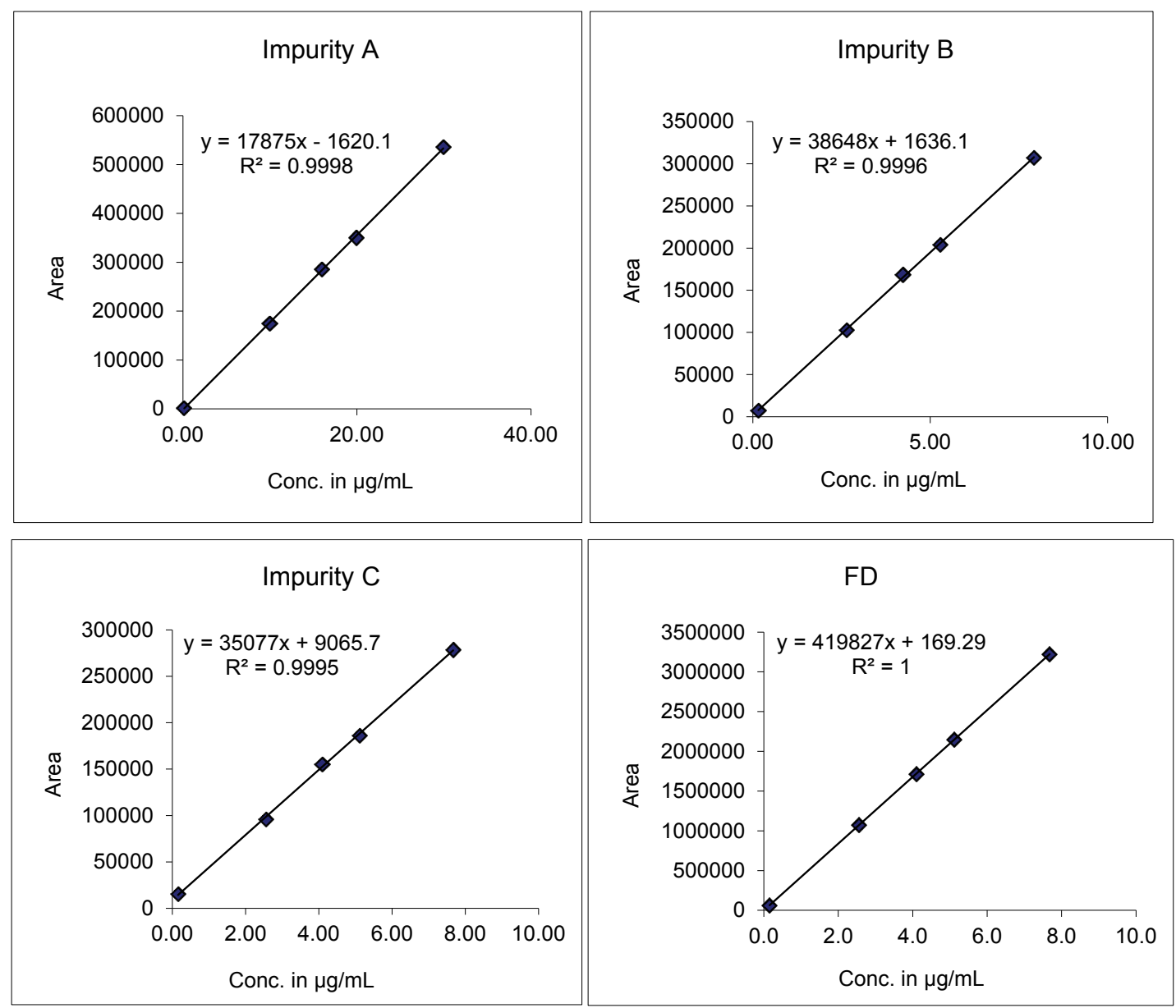

Figure 22: Linearity graphs.

\begin{tabular}{|c|c|c|c|c|c|c|c|c|c|}
\hline \multirow{2}{*}{$\begin{array}{l}\text { Name of the } \\
\text { compound }\end{array}$} & \multicolumn{6}{|c|}{ Concentration in \% } & \multirow{2}{*}{ Average } & \multirow{2}{*}{ SD } & \multirow[b]{2}{*}{$\%$ RSD } \\
\hline & 1 & 2 & 3 & 4 & 5 & 6 & & & \\
\hline $\operatorname{Imp} \mathrm{A}$ & 2.0602 & 2.0571 & 2.0590 & 2.0581 & 2.0576 & 2.0576 & 2.0583 & 0.001 & 0.1 \\
\hline Imp B & 0.5475 & 0.5470 & 0.5484 & 0.5482 & 0.5479 & 0.5480 & 0.5478 & 0.001 & 0.1 \\
\hline Imp C & 0.5285 & 0.5293 & 0.5262 & 0.5280 & 0.5278 & 0.5273 & 0.5279 & 0.001 & 0.2 \\
\hline
\end{tabular}

Table 12: Results for method precision.

\begin{tabular}{|c|c|c|c|c|c|c|c|c|c|c|c|c|}
\hline \multirow[b]{2}{*}{$\begin{array}{l}\text { Name of the } \\
\text { component }\end{array}$} & 1 & 2 & 3 & 4 & 5 & 6 & 7 & 8 & 9 & \multirow[b]{2}{*}{ Average } & \multirow[b]{2}{*}{ SD } & \multirow[b]{2}{*}{$\%$ RSD } \\
\hline & \multicolumn{3}{|c|}{$\begin{array}{c}\text { Analyst } 1 \\
\text { Day } 1 \\
\text { Instrument } 1\end{array}$} & \multicolumn{3}{|c|}{$\begin{array}{c}\text { Analyst } 2 \\
\text { Day } 2 \\
\text { Instrument } 1\end{array}$} & \multicolumn{3}{|c|}{$\begin{array}{c}\text { Analyst } 1 \\
\text { Day } 3 \\
\text { Instrument } 2\end{array}$} & & & \\
\hline $\operatorname{Imp} A$ & 2.060 & 2.057 & 2.059 & 2.061 & 2.058 & 2.061 & 2.070 & 2.054 & 2.067 & 2.061 & 0.005 & 0.2 \\
\hline Imp B & 0.548 & 0.547 & 0.548 & 0.548 & 0.550 & 0.554 & 0.544 & 0.552 & 0.551 & 0.549 & 0.003 & 0.5 \\
\hline Imp C & 0.529 & 0.529 & 0.526 & 0.527 & 0.529 & 0.527 & 0.525 & 0.522 & 0.525 & 0.527 & 0.002 & 0.4 \\
\hline
\end{tabular}

Table 13: Precision data of proposed RP-HPLC method.

\begin{tabular}{|c|c|c|c|c|c|}
\hline Name of the component & $\begin{array}{c}\text { Mean recovery of } \\
\text { LOQ }\end{array}$ & $\begin{array}{c}\text { Mean recovery of } \\
\mathbf{5 0 \%}\end{array}$ & $\begin{array}{c}\text { Mean recovery of } \\
\mathbf{1 0 0 \%}\end{array}$ & $\begin{array}{c}\text { Mean recovery of } \\
\mathbf{1 5 0} \%\end{array}$ & $\begin{array}{c}\text { \% RSD (precision) } \\
\text { SD }\end{array}$ \\
\hline Imp A & 95.4 & 103.3 & 103.2 & 103.4 & 4.0 \\
\hline Imp B & 96.0 & 105.7 & 103.7 & 102.4 \\
\hline Imp C & 96.3 & 96.4 & 103.3 & 4.2 & 101.6 \\
\hline
\end{tabular}

Table 14: Accuracy. 
Citation: Vadlamudi MK, Dhanaraj S (2016) Stability Indicating Method for the Determination of Related Substances in Felodipine Solid Dosage Form and in the Drug Substance by RP-HPLC. J Bioequiv Availab 8: 153-166. doi:10.4172/jbb.1000287

\begin{tabular}{|c|c|c|c|c|c|}
\hline \multirow{2}{*}{ Actual condition } & \multirow{2}{*}{ Changed condition } & \multirow{2}{*}{ USP Theoretical Plates (N) } & \multirow{2}{*}{ USP Tailing factor $(\mathrm{T})$} & \multicolumn{2}{|c|}{ USP resolution between FD and } \\
\hline & & & & $\operatorname{Imp} A$ & $\operatorname{Imp} C$ \\
\hline \multirow{6}{*}{$0.7 \mathrm{~mL} / \mathrm{min}$} & \multirow{3}{*}{$0.6 \mathrm{~mL} / \mathrm{min}$} & FD: 3934 & FD: 1.32 & \multirow{3}{*}{2.7} & \multirow{3}{*}{6.3} \\
\hline & & Imp A: 4050 & Imp B: 1.21 & & \\
\hline & & Imp C: 4413 & Imp C: 1.25 & & \\
\hline & \multirow{3}{*}{$0.8 \mathrm{~mL} / \mathrm{min}$} & FD: 3476 & FD: 1.28 & \multirow{3}{*}{2.4} & \multirow{3}{*}{6.0} \\
\hline & & Imp A: 3541 & $\operatorname{Imp} A: 1.18$ & & \\
\hline & & Imp C: 3965 & Imp C: 1.19 & & \\
\hline \multirow{6}{*}{$240 \mathrm{~nm}$} & \multirow{3}{*}{$238 \mathrm{~nm}$} & FD: 4192 & FD: 1.26 & \multirow{3}{*}{2.6} & \multirow{3}{*}{6.2} \\
\hline & & Imp A: 4150 & $\operatorname{Imp} A: 1.14$ & & \\
\hline & & Imp C: 4689 & Imp C: 1.17 & & \\
\hline & \multirow{3}{*}{$242 \mathrm{~nm}$} & FD: 4169 & FD: & \multirow{3}{*}{2.6} & \multirow{3}{*}{6.2} \\
\hline & & Imp A: 4196 & $\operatorname{Imp} A:$ & & \\
\hline & & Imp C: 4598 & Imp C: & & \\
\hline \multirow{6}{*}{$25^{\circ} \mathrm{C}$} & \multirow{3}{*}{$20^{\circ} \mathrm{C}$} & FD: 3566 & FD: 1.32 & \multirow{3}{*}{2.7} & \multirow{3}{*}{6.3} \\
\hline & & Imp A: 3656 & $\operatorname{Imp} A: 1.21$ & & \\
\hline & & Imp C: 4100 & Imp C: 1.20 & & \\
\hline & \multirow{3}{*}{$30^{\circ} \mathrm{C}$} & FD: 3985 & FD: 1.32 & \multirow{3}{*}{2.5} & \multirow{3}{*}{6.1} \\
\hline & & Imp A: 4001 & $\operatorname{Imp} A: 1.21$ & & \\
\hline & & Imp C: 4546 & Imp C: 1.21 & & \\
\hline \multirow{6}{*}{$5.0 \mathrm{pH}$} & \multirow{3}{*}{$4.9 \mathrm{pH}$} & FD: 3578 & FD: 1.30 & \multirow{3}{*}{2.3} & \multirow{3}{*}{5.9} \\
\hline & & Imp A: 3415 & $\operatorname{Imp} A: 1.19$ & & \\
\hline & & Imp C: 4021 & Imp C: 1.18 & & \\
\hline & & FD: 4126 & FD: 1.31 & & \\
\hline & $5.1 \mathrm{pH}$ & Imp A: 3945 & $\operatorname{Imp} A: 1.20$ & 2.6 & 6.4 \\
\hline & & Imp C: 4356 & Imp C: 1.21 & & \\
\hline & & FD: 4092 & FD: 1.25 & & \\
\hline & $\begin{array}{c}\text { Column } 1 \text { Lot No: } \\
5520-60\end{array}$ & Imp A: 4140 & Imp A: 1.16 & 2.6 & 6.2 \\
\hline Column & & Imp C: 4673 & Imp C: 1.17 & & \\
\hline column & & FD: 4510 & FD: 1.19 & & \\
\hline & $\begin{array}{c}\text { Column } 2 \text { Lot No: } \\
5520-66\end{array}$ & Imp A: 4351 & $\operatorname{Imp} A: 1.06$ & 2.6 & 6.2 \\
\hline & & Imp C: 4821 & Imp C: 1.11 & & \\
\hline
\end{tabular}

Table 15: Robustness.

\begin{tabular}{|c|c|c|c|c|c|}
\hline Data Evaluated & Initial & Day-1 & Day-2 & Day-3 & \%ariation \\
\hline Imp A & 2.061 & 2.131 & 2.216 & 11.5 \\
\hline Imp B & 0.548 & 0.555 & 0.564 & 0.570 \\
\hline Imp C & 0.529 & 0.533 & 0.539 & 0.543 \\
\hline
\end{tabular}

Table 16: Solution stability at room temperature $\left(25^{\circ} \mathrm{C}\right)$.

\begin{tabular}{|c|c|c|c|c|c|}
\hline Data Evaluated & Initial & Day-1 & Day-2 & Day-3 & 2.078 \\
\hline Imp A & 2.061 & 2.065 & 2.071 & 0.8 \\
\hline Imp B & 0.548 & 0.549 & 0.551 & 0.553 \\
\hline Imp C & 0.529 & 0.530 & 0.530 & 0.533 \\
\hline
\end{tabular}

Table 17: Solution stability at refrigerator $\left(5^{\circ} \mathrm{C}\right)$.

\begin{tabular}{|c|c|c|c|c|}
\hline Name of impurity & Drug substance-1 & Drug substance-2 & Formulation-1 & Formulation-2 \\
\hline Imp A (\%) & 0.00 & 0.01 & 0.02 & 0.39 \\
\hline $\operatorname{Imp~B~(\% )~}$ & 0.03 & 0.04 & 0.05 & 0.25 \\
\hline $\operatorname{Imp~C~(\% )~}$ & 0.24 & 0.22 & 0.25 & $<=2.0$ \\
\hline
\end{tabular}

Table 18: Sample analysis results.

hence this method can be used for the regular analysis and also for the stability testing of the samples.

\section{Acknowledgement}

The authors express their gratitude towards the department of analytical research and development, Ashland India Private Limited, Hyderabad, Telangana, India for the support in terms of research facilities and samples.

\section{References}

1. Annapurna, MM, Kumar BSP, Goutam SVS (2013) Stability-indicating RPHPLC method for the determination of felodipine (a calcium channel blocker) in tablets. Indo American Journal of Pharmaceutical Research 3: 9277-9285.

2. Williams $M(2013)$ The Merck index: an encyclopedia of chemicals, drugs, and biologicals. O'Neil MJ 15 ${ }^{\text {th }}$ (Edn), RSC Publishing 74: 339 
Citation: Vadlamudi MK, Dhanaraj S (2016) Stability Indicating Method for the Determination of Related Substances in Felodipine Solid Dosage Form and in the Drug Substance by RP-HPLC. J Bioequiv Availab 8: 153-166. doi:10.4172/jbb.1000287

3. Nyborg NCB, Mulvany MJ (1984) Effect of felodipine, a new dihydropyridine vasodilator, on contractile responses to potassium, noradrenaline, and calcium in mesenteric resistance vessels of the rat. J Cardiovasc Pharmacol 6: 499-505.

4. Hu L, Hu Q, Na G (2013) A validated, stability-indicating HPLC method for the determination of Felodipine and its related substances. International Journal of Pharmaceutical Sciences and Research 4:3369-3374.

5. Walash MI, Belal FF, El-Enany NM, El-Maghrabey MH (2011) Synchronous fluorescence spectrofluorimetric method for the simultaneous determination of metoprolol and felodipine in combined pharmaceutical preparation. Chem Cent J 5: 70.

6. Bazzo GC, Caetano DB, Boch ML, Mosca M, Branco LC, et al. (2012)
Enhancement of felodipine dissolution rate through its incorporation into Eudragit $^{\circledR}$ E-PHB polymeric microparticles: in vitro characterization and investigation of absorption in rats. J Pharm Sci 101: 1518-1523.

7. Singh S, Bakshi M (2000) Stress test to determine inherent stability of drugs. Pharmaceutical technology 4: 1-14.

8. Szepesi G, Gazdag M, Mihalyfi K (1991) Selection of high-performance liquid chromatographic methods in pharmaceutical analysis: III. Method validation. J Chromatogr 464: 265-278.

9. (1996) ICH, "Validation of Analytical Procedures: Methodology," Proceeding of the International Conference on Harmonization, Geneva. 